\title{
Salami Publication: An Outlook from the Lens of Ethical Perspective
}

\author{
Manisha Koul ${ }^{1}$, Prasanta Majumder ${ }^{2}$, Shyamalendu Laskar ${ }^{3}$
}

\begin{abstract}
In the increasing quest for the publication of research papers, the authors become overzealous to section their research articles which can help in portraying a big number of research papers for the credit of the author. The scientist community and the medical fraternity value the researcher based on their number of publications with the researcher having a smaller number of so-called acceptable number of research papers getting vanished in the crowd of renowned researchers. This narrative review aims at exploring the ethical considerations related to salami publication (salami slicing) in research. It was concluded that salami slicing is not entirely an ethical misconduct. However, authors and editors of the journals have a liability to protect the research integrity by stating that this piece of research is a salami publication.

Keywords: Publication ethics, Research ethics, Salami publication, Salami slicing.

Journal of Oral Health and Community Dentistry (2021): 10.5005/jp-journals-10062-0099
\end{abstract}

\section{INTRODUCTION}

Every researcher has an occult desire of publishing his/her research work. Publishing research articles has become important in many fields, especially in the medical profession. With this, every researcher is likely to face the stress of increasing the number of publications over a period of time. ${ }^{1}$ This brings to notice the sudden upsurge in the number of research paper achievements with a deliberate attempt of segmenting the data so that it can be presented in a segmented form in multiple journals. Although the relevance rate of salami publication is difficult to estimate, the available literature suggests a prevalence rate of $1-12 \% .{ }^{2,3}$ Only a few journals have been observed to have specific author instructions pertaining to salami slicing. This is derived from the quest for a larger number of research articles. The trend of salami slicing is especially evident in medical science and social sciences. ${ }^{4}$ The rising trend of salami publication raises a question on the quality of research documented in the journals. The aim of this review is to explore the ethical perspectives related to salami publication in the research.

\section{Salami Publication and Duplicate Publication}

Salami publication or precisely called salami slicing refers to splitting the data collected from a single research into a number of research articles, each of which is published separately in different journals. ${ }^{3}$ Although unethical, duplicate as well as salami publications are increasing in number, salami publication is deemed to be detrimental to the scientific community. In a handful of journals, journal policies to curb salami publication are present. In contrast, duplicate publication refers to the publication of the same research in multiple journals. ${ }^{5}$

\section{Theoretical Understanding of Salami Publication}

Assessing the theoretical perspectives underpinning the emergence of salami publication, Mertonian theory of cumulative
${ }^{1}$ Rajiv Gandhi University of Health Sciences, Bengaluru, Karnataka, India

${ }^{2}$ Department of Public Health Dentistry, Coorg Institute of Dental Sciences, Bengaluru, Karnataka, India

${ }^{3}$ Department of Oral and Maxillofacial Surgery, Index Institute of Dental Sciences, Madhya Pradesh, India

Corresponding Author: Manisha Koul, Rajiv Gandhi University of Health Sciences, Bengaluru, Karnataka, India, Phone: +91 8296780696, e-mail: manishakoul.13@gmail.com

How to cite this article: Koul M, Majumder P, Laskar S. Salami Publication: An Outlook from the Lens of Ethical Perspective. J Oral Health Comm Dent 2021;15(2):84-86.

Source of support: Nil

Conflict of interest: None

advantages specifies that salami publication bears a reasonable impact on upholding the prestige of the researcher by mentioning an astonishingly higher number of publications. The number of publications is directly linked to the number of citations. ${ }^{3,6}$ This indicates the probable reason for researchers to be attracted to the phenomenon of multiple fragment researches. Acknowledging the demographic inconsistencies, contrasting results have been found. The majority of the budding researches concluded that young researchers are in the race of competing to publish more numbers of articles. ${ }^{7}$ On the contrary, some of the studies have found that the younger researchers are naïve to indulge in salami publication. $^{8}$

\section{Practice of Salami Slicing}

The budding researchers indulge in the practice of salami slicing by extensive isolation of the information collected during the process of data collection. Dhakal ${ }^{9}$ specified that when a study involves several correlates or independent variables, the rescuer tends to segregate the effect of independent variables as independent correlates, ignoring the cumulative effect of the independent (predictor) variables on the dependent (outcome) 
variables. Similarly, some of the authors have reported that some of the researchers manipulate the post hoc subgroup analysis in order to derive multiple effects. ${ }^{6}$

Currently, we have research tools to check for plagiarism; however, there is no research tool to gauge the practice of salami publication. According to Pfleegor et al., ${ }^{10}$ salami slicing of qualitative data is even more difficult to detect than the clinical trials due to compulsory registration of ongoing randomized trials in a clinical trial registry maintained by the government. Thus, researchers have vital accountability for determining the use of one study in a fragmented portion. As per $\mathrm{Ma},{ }^{11}$ keeping the salami slicing out of the umbrella of misconduct can promote researchers to accept that the piece of research has been fragmented framing the main research. This will also help readers assess the facts and figures associated with the original research.

\section{Ethical Perspectives in Salami Publication}

Ethics refers to the set of norms for the conduct of research and its publication in a fair manner. ${ }^{12}$ Adherence to ethical standards is essential to promote the quality of research, especially in the medical field. Salami slicing has been found to be borne out of publish-or-perish culture wherein nonpublishing of research disfavors the academic success for the researchers. ${ }^{8,10}$ The escalating trends of salami slicing draw attention to the potential role of ethics in this field. Here comes in light the necessary question that whether salami publication is unethical or ethical dilemma. Duplicate publication is an unethical conduct as per the Committee on Publication Ethics guidelines. However, no such comments have been made for salami publication. ${ }^{12}$

Evaluating the ethics in salami publication, it can be viewed that it is not a huge misconduct or falsification as a single study may involve different variables and thus the interrelationships between the variables may vary. Natarajan ${ }^{13}$ mentioned that for salami publication, the researchers are inclined to publish one research article unit with minimal information acquired from the main study. It was supported by the study conducted by Urbanowicz and Reinke ${ }^{14}$ by stating that it is not a fraud to publish a large study in parts and there is no evidence of distortion of facts in salami publication. Moreover, ${ }^{15}$ it was specified that it may not be easier for the readers to gulp the excess information provided by a research in one go. To make the reach publication comprehensive, salami slicing permits the dissemination of information in an amount that is easy to comprehend for the readers. Similarly, Joob and Wiwanitkit ${ }^{5}$ mentioned that publication of a thesis in the form of research articulateness is impossible unless slicing of data is done to "fit in" the journal manuscripts. The authors further mentioned that any journal at the maximum accepts a research article of 3,000 words whereas a research thesis usually accounts for 15,000-20,000 words. Thus, to publish a manuscript for journals, the researcher's area compels to perform salami slicing.

Studies against salami publication report that such publications are focused on the quantity rather than the quality of the research. In addition to this, it is perceived to be a case of data dredging. ${ }^{2,9}$ Rao and Andrade ${ }^{16}$ mentioned that it is unethical to practice salami slicing as it will be misleading the audience namely healthcare professionals and researchers. The flawed research reported in split forms in multiple journals overestimates the causal role of the variables on the disease and illness. ${ }^{11}$ Adding on Smart ${ }^{3}$ indicated that salami slicing perpetuates an unnecessary burden on the journal editors and reviewers. According to Deshmukh et al., ${ }^{17}$ salami slicing is a dishonest practice to waste the time of readers. Salami publication stems from academic pressure for career advancement to push the researchers to enhance their number of researches.

In contrast to the above-mentioned ethical perspectives governing salami slicing, a few studies regard this as an ethical dilemma for researchers which predicates their intention of increasing their number of cited publications. One of the researches mentioned that salami publication is an ethical dilemma rather than unethical practice. ${ }^{18}$ The researchers experience the dilemma that whether they should fragment their research or they shall publish it as a whole. It was further highlighted that researchers encounter conflicts regarding how much amount of data fragmentation is permissible to uphold the ethics in research publication. Theoretically, there is no scale to measure the permissible amount of data slicing from a single research. ${ }^{4,5}$ This is juxtaposed by the knowledge and intention of the researcher.

\section{Interventions to Reduce the Occurrence of Salami Publications}

Salami slicing is not entirely unethical. It stays justified when slicing of the research papers is done because some research topics are large and thus for answering that research question a large amount of data is collected in the process of research. ${ }^{19}$ However, this practice shall be discouraged among the researchers to reduce any sort of biased opinion arising out of the fragmentation of data. The sliced publication may lose focus on the effect of confounding factors as a whole in describing the disease causation or the treatment effect of the interventions used in the original/main study. To mitigate the practice of salami publication, interventions need to be focused on the researchers as well as journal policies. The journals need to practice strict policies regarding the information obtained from authors pertaining to the main research they have conducted. ${ }^{6,14}$

Furthermore, the researchers need to be cautious regarding the ethical implications of salami slicing. It is recommended to the journals to add a column in the article clearly stating the standpoint of authors mentioning that whether it is a salami publication or the main research study. ${ }^{1,16,18}$ This will be valuable for the reader to access the main research to arrive at definite conclusions. Last, to protect the integrity of research, it is recommended to reduce the unnecessary burden of publishing a large number of researches to gain a qualitative edge in a career.

\section{Conclusion}

With a sharp rise in the published research articles, keen thoughtfulness provokes attention to salami slicing. Due to the reported inconsistencies in journal policies to report salami publication, it becomes extremely difficult to restrict this practice of slicing the data into multiple numbers of researches. Salami publication is not the same as duplicate publication, which by large is an established publication misconduct. Salami publication is ethical as far as the researcher does not distort the facts in the context of the research question. It can be concluded that although it is not exclusively an unethical conduct salami slicing shall not be encouraged. Salami publication is acceptable when there is no blatant falsification of the study results for the sake of increasing the number of research publications. The decision regarding salami publication is quite intriguing. With attractive academic benefits in the context of a career, there is a potential inclination toward salami publication. This review presented a snapshot of reasons for salami 
publication and its associated ethical concerns. This review adds to the literature findings by substantiating the fact that the researchers and editors need to be aware of the trivial differences in plagiarism, duplication, and salami publication. Further research is warranted to assess the possible solutions to deal with the issue of salami publication to shed further light on the practice of salami slicing and its effect on the evidence-based research. To maintain transparency, the researchers can quote their main study in the methodology section. This will reduce the incidence of bias incorporated due to the splitting of data in the research articles.

\section{References}

1. Menon V, Muraleedharan A. Salami slicing of data sets: what the young researcher needs to know. Indian J Psychol Med 2016;38(6):577-578. DOI: 10.4103/0253-7176.194906.

2. Ding D, Nguyen B, Gebel K, et al. Duplicate and salami publication: a prevalence study of journal policies. Int J Epidemiol 2020;49(1):281288. DOI: $10.1093 /$ ije/dyz187.

3. Smart P. Redundant publication and salami slicing: the significance of splitting data. Dev Med Child Neurol 2017;59(8):775. DOI: 10.1111/ dmcn.13485.

4. Wallace $M B$, Bowman $D$, Hamilton-Gibbs $H$, et al. Ethics in publication, part 2: duplicate publishing, salami slicing, and large retrospective multicenter case series. Gastrointest Endosc 2018;87(5):1335-1337. DOI: 10.1016/j.gie.2018.01.002.

5. Joob B, Wiwanitkit V. Salami slicing of data set, translational plagiarism, and self-plagiarism: the storyline. Indian J Psychol Med 2017;39(2):218. DOI: 10.4103/0253-7176.203131.

6. Collyer TA. "Salami slicing" helps careers but harms science. Nat Hum Behav 2019;3(10):1005-1006. DOI: 10.1038/s41562-019-0687-2.

7. Eva KW. How would you like your salami? A guide to slicing. Med Educ 2017;51(5):456-457. DOI: 10.1111/medu.13285.
8. Boeckstyns ME, Giddins G, Meals R, et al. Publication ethics. J Hand Surg (European Volume) 2020;45(7):770-774. DOI: $10.1177 / 1753193420905263$.

9. Dhakal RK. Responsible practice of research: safeguarding research integrity and publication ethics. J Educ Res 2016;6(2):1-11. DOI: 10.3126/jer.v6i2.22144.

10. Pfleegor AG, Katz M, Bowers MT. Publish, perish, or salami slice? Authorship ethics in an emerging field. J Bus Ethics 2019;156(1): 189-208. DOI: 10.1007/s10551-017-3578-3.

11. Ma W. Problematic nature of self-plagiarism: an ethical grey area. Publish Action 2018;1:39-47.

12. Ali Z, Ali A. Violation of publication ethics: a growing concern for journal editors. J Postgrad Med Inst (Peshawar-Pakistan) 2017;31(4). Available from: https://jpmi.org.pk/index.php/jpmi/article/ view/2282

13. Natarajan S. Salami publishing: walking on thin (sl)ice. Indian $J$ Ophthalmol 2016;64(12):869. DOI: 10.4103/0301-4738.198848.

14. Urbanowicz C, Reinke BA. Publication overlap: building an academic house with salami shingles. Bull Ecol Soc Am 2018;99(4):1-6. DOI: 10.1002/bes2.1425.

15. Chadha M, Jain AK. Ethical issues while reporting in scientific journals. Indian Spine J 2020;3(1):1. DOI: 10.4103/isj.isj_2_20.

16. Rao TS, Andrade C. Part publication: when it is ethical and when it is not. Indian J Psychiatry 2016;58(4):357. DOI: 10.4103/00195545.196725 .

17. Deshmukh MA, Dodamani AS, Khairnar MR, et al. Research misconduct: a neglected plague. Indian J Public Health 2017;61(1):33. DOI: 10.4103/0019-557X.200255.

18. Yip C, Han NL, Sng BL. Legal and ethical issues in research. Indian J Anaesth 2016;60(9):684. DOI: 10.4103/0019-5049.190627.

19. Hays $R$, Masters K. Publishing ethics in medical education: guidance for authors and reviewers in a changing world. MedEdPublish 2020;9. DOI: 10.15694/mep.2020.000048.1. 